\title{
Penentuan Rute Transportasi untuk Meminimalkan Biaya Menggunakan Metode Nearest Neighbor dan Nearest Insert (Studi Kasus dalam Pendistribusian Sandal di Tasikmalaya)
}

\author{
Mutia Rohmah ${ }^{1,}$ a), Elis Ratna Wulan ${ }^{1, b)}$, Fadilah Ilahi ${ }^{1, c)}$ \\ ${ }^{1}$ Program Studi Matematika, Fakultas Sains dan Teknologi, UIN Sunan Gunung Djati, Bandung \\ a)email:mutiarhmh37@gmail.com \\ ${ }^{b)}$ email: elis ratna wulan@uinsgd.ac.id \\ c)email: fadilah.ilahi@uinsgd.ac.id
}

\begin{abstract}
Abstrak
Vehicle Routing Problem (VRP) merupakan penentuan sebuah set rute yang dilakukan oleh sebuah kendaraan dimulai perjalanan dari depot untuk memenuhi permintaan konsumen. Salah satu jenis dari VRP adalah Capacitated Vehicle Routing Problem (CVRP) yaitu VRP yang memiliki batasan kapasitas kendaraan. Tujuan penulisan artikel ini untuk menentukan rute distribusi sandal di Tasikmalaya dengan menyelesaikannya menggunakan metode Saving Matrix untuk menentukan penjadwalan rute kendaraan sesuai dengan kapasitas kendaraan berdasarkan penghematan terbesar dan menggunakan metode Nearest Neighbour dan metode Nearest Insert dalam menentukan urutan lokasi. Serta mengetahui penyelesaian CVRP yang paling efektif dari metode tersebut.Metode Nearest Neighbour mempertimbangkan jarak yang terdekat sedangkan metode Nearest Insert penentuan lokasi penyisipan. Berdasarkan perhitungan yang dilakukan dalam menyelesaikan CVRP menggunakan metode Nearest Neighbour diperoleh total jarak tempuh yaitu $1.379,9 \mathrm{~km}$ dan dengan metode Nearest Insert diperoleh total jarak tempuh 1.376,3 km. Sedangkan total jarak tempuh perusahaan saat ini yaitu $2.639,1 \mathrm{~km}$. hal ini menunjukkan bahwa metode Nearest Insertlebih efektif dalam menentukan rute distribusi sandal di Tasikmalaya.
\end{abstract}

Kata kunci: Rute, Jarak, Saving Matrix, Nearest Neighbour, Nearest Insert, Vehicle Routing Problem.

\begin{abstract}
Vehicle Routing Problem (VRP) is the determination of a set of routes carried out by a vehicle starting from a trip from a depot to meet consumer demand. One type of VRP is Capacitated Vehicle Routing Problem (CVRP), which is VRP which has limits on vehicle capacity. The purpose of this thesis is to determine the slippers distribution route in Tasikmalaya by completing it using the Saving Matrix method to determine the scheduling of vehicle routes according to vehicle capacity based on the largest savings and using the Nearest Neighbor method and the Nearest Insert method in determining the sequence of locations. And find out the most effective CVRP implementation of the method. The Nearest Neighbor method considers the closest distance while the Nearest Insert method has advantages in determining the insertion location. Based on the calculations made in completing VRP using the Nearest Neighbor method, the total distance traveled is obtained1,379.9 $\mathrm{km}$, and with the nearest insert method the total distance traveled is obtained 1,376.3 km. Whereas the total distance traveled by the company is now2,639.1 km. this shows that the nears insert method is more effective in determining the flip distribution route in Tasikmalaya.
\end{abstract}


Keywords: Route, Distance, Saving Matrix, Nearest Neighbour, Nearest Insert, Vehicle Routing Problem.

\section{Pendahuluan}

Sebagai perusahaan yang bergerak dalam bidang distribusi, penentuan rute pengiriman sangat penting untuk mempertimbangkan efesiensi waktu dan meminimalkan biaya transportasi [1]. Sehingga diperlukan ketepatan dalam menentukan rute terbaik. Rute terbaik adalah rute dengan jarak terpendek, yang tentunya akan mempengaruhi biaya transportasi yang dikeluarkan. Semakin pendek jarak tempuh dari kendaraan maka biaya transportasinya pun lebih rendah.

Sebagaimana firman Allah swt dalam Al-Qur'an surah Saba': 18

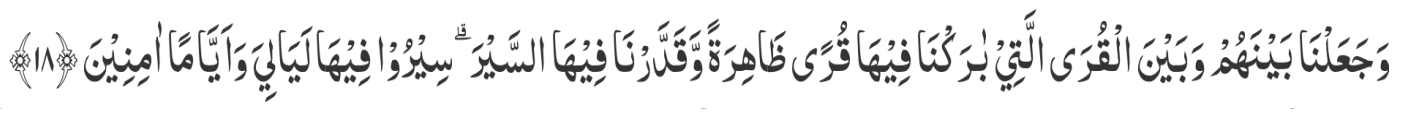

"Dan kami jadikan antara mereka dan antara negeri-negeri yang Kami limpahkan berkat kepadanya, beberapa negeri yang nampak dan Kami tetapkan padanya perjalanan (dekat).Berjalanlah di dalamnya pada malam dan siang hari dengan aman."

Ayat di atas menjelaskan bahwa dengan limpahan berkat Allah Swt dalam menciptakan negeri-negeri terdapat jarak dari negeri yang satu ke negeri yang lainnya, ada yang berjauhan dan ada pula yang berdekatan untuk memudahkan orang melaluinya. Sehingga dapat dipahami bahwa jarak diantara negeri tersebut berbeda-beda.

Dalam ilmu matematika penentuan sebuah set rute dimana setiap rute tersebut dilakukan oleh sebuah kendaraan yang memulai perjalanan dari depot untuk memenuhi permintaan konsumen tanpa melanggar batasan-batasan yang diterapkan serta dapat meminimasi biaya transportasi disebut VRP (Vehicle Routing Problem) [2]. Dimana sebuah kota diasosiasikan sebagai sebuah demand atau konsumen dan tiap kendaraan yang dipakai untuk perjalanan dianggap memiliki kapasitas tertentu.

Beberapa contoh batasan-batasan yang diberikan adalah kapasitas kendaraan, keterbatasan aksesbilitas konsumen, permintaan pick-upsdelivery dan time windows atau kendala waktu. Untuk memenuhi permintaan pelanggan dengan jumlah muatan yang tidak melampaui kapasitas, maka digunakan Capacitated Vehicle Routing Problem (CVRP) yaitu setiap kendaraan mempunyai kapasitas tertentu. Permasalahan CVRP yang akan diteliti pada penelitian ini adalah pendistribusian sandal di Tasikmalaya.

Dalam menyelesaikan CVRP terdapat tiga metode yang akan dikaji, yaitu metode Saving Matrix, metode Nearest Neighbour dan metode Nearest Insert. Penggunaan metode Saving Matrix untuk menentukan penjadwalan kendaraan sesuai dengan kapasitas muatan ke daerah pengiriman berdasarkan penghematan terbesar dan menggunakan metode Nearest Neighbour dan metode Nearest Insert dalam menentukan urutan lokasi. Sehingga dilakukan perbandingkan metode Nearest Neighbour dan Nearest Insert untuk menentukan rute terbaik.

\section{Studi Kasus dan Model}

Kayungyun merupakan salah satu perusahaan yang bergerak dalam bidang pendistribuisan sandal yang berlokasi di kota Tasikmalaya. Perusahaan menjual sandal dengan berbagai macam jenis dan telah memasok sebagaian besar wilayah di kota Bandung. Untuk megirim barang ke setiap konsumen, perusahaan menyediakan kendaraan pengangkut berupa mobil box. Mobil tersebut digunakan setiap harinya untuk mengirimkan barang dari pabrik $\mathrm{G}$ menuju konsumen dengan rute 
yang telah ditentukan. Mobil mulai pemberangkatan pada pagi hari pukul $05.00 \mathrm{WIB}$ hingga selesai. Rata-rata dengan kondisi yang ada, sebuah mobil mampu kembali ke perusahaan kota tasikmalaya pada pukul 21.00 WIB. Bahan bakar yang disediakan untuk pendistribusian sandal adalah berupa solar yang diasumsikan harga bahan bakar Rp.9000/liter.

Perusahaan ini memiliki 1 unit pick up yang digunakan dalam proses pendistribusian sandal dengan kapasitas kendaraannya hanya mampu mengangkut maksimal 270 kodi. Lokasi antar pelanggan tersebar di daerah Bandung dengan memiliki 20 pelanggan. Rute awal perusahaan berjumlah 10 rute, dimana rute awal perusahaan dengan mengirimkan barang ke dua konsumen yaitu gudang-konsumen 1-konsumen 2-gudang.

Berdasarkan analisis data dari perusahaan sandal yang ada di Tasikmalaya dan rute kendaraan pendistribusian sandal. Saat ini dalam mendistribusikan sandal belum optimal dalam hal jarak, kapasitas kendaraan, maupun biaya transportasi.Sehingga diperlukan suatu perbaikan rute yang lebih efesien.

Masalah yang dialami Kayungyun ini termasuk ke dalam permasalahan CVRP karena dibatasi oleh kapasitas kendaraan. Penentuan rute kendaraan yang efektif adalah yang dapat meminimalkan jarak dan menghemat biaya transportasi dengan tetap memaksimalkan kapasitas kendaraan yang digunakan dalam proses pendistribusian.

Oleh karena itu, mobil akan membentuk rute baru untuk menyelesaikan proses pendistribuian sandal yang tidak dimaksimalkan pada rute sebelumnya. Hal tersebut tentu saja berpengaruh terhadap pengeluaran yang dikeluarkan oleh perusahaan sandal kota Tasikmalaya. Oleh karena itu, diperlukan suatu model matematis yang dapat menghasilkan rute dengan total jarak minimum serta mempertimbangkan kapasitas mobil.

Tabel 1. Data konsumen

\begin{tabular}{ccc}
\hline Kode & $\begin{array}{c}\text { Alamat } \\
\text { konsumen }\end{array}$ & $\begin{array}{c}\text { Permintaan } \\
\text { konsumen }\end{array}$ \\
\hline K1 & Ciroyom & 30 \\
K2 & Andir & 45 \\
K3 & Ciwastra & 75 \\
K4 & Buah Batu & 60 \\
K5 & Ujung Berung & 50 \\
K6 & Kiara Condong & 70 \\
K7 & Gede Bage & 62 \\
K8 & Sukajadi & 45 \\
K9 & Caringin & 35 \\
K10 & Cimahi & 60 \\
K11 & Ciwidey & 120 \\
K12 & Lembang & 52
\end{tabular}

Tabel 2. Rute awal dan jarak

\begin{tabular}{ccc}
\hline No. & Rute konsumen & Jarak (km) \\
\hline 1 & G-K1- K2-G & 258.7 \\
2 & G-K3-K4-G & 240.8 \\
3 & G-K5-K6-G & 240 \\
4 & G-K7-K8-G & 258 \\
5 & G-K9-K10-G & 267 \\
6 & G-K11-K12-G & 349 \\
7 & G-K13-K14-G & 240 \\
8 & G-K15-K16-G & 268.1 \\
9 & G-K17-K18-G & 244.2 \\
10 & G-K19-K20-G & 273.3
\end{tabular}




\begin{tabular}{ccc}
\hline Kode & $\begin{array}{c}\text { Alamat } \\
\text { konsumen }\end{array}$ & $\begin{array}{c}\text { Permintaan } \\
\text { konsumen }\end{array}$ \\
\hline K13 & Cikutra & 100 \\
K14 & Cicaheum & 90 \\
K15 & Dago & 45 \\
K16 & Sumur & 75 \\
K17 & Cibeunying & 65 \\
K18 & Citarum & 60 \\
K19 & Sarijadi & 80 \\
K20 & Pamoyanan & 30 \\
\hline
\end{tabular}

Tabel 3. Biaya transportasi awal

\begin{tabular}{|c|c|c|c|c|c|c|c|}
\hline No & $\begin{array}{c}\text { Jarak } \\
\text { (km) }\end{array}$ & BBM & Jasa & Perawatan & Retribusi & $\begin{array}{l}\text { Pajak } \\
\text { mobil }\end{array}$ & Total (Rp) \\
\hline \multirow[t]{2}{*}{1} & & & & & & & \\
\hline & 258.7 & 194.025 & 350.000 & 200.000 & 200.000 & 25.000 & 969.025 \\
\hline \multirow[t]{2}{*}{2} & & 180.600 & & & & & 955.600 \\
\hline & 240.8 & 180.600 & 350.000 & 200.000 & 200.000 & 25.000 & 953.600 \\
\hline 3 & 240 & 180.000 & 350.000 & 200.000 & 200.000 & 25.000 & 955.000 \\
\hline 4 & 258 & 193.500 & 350.000 & 200.000 & 200.000 & 25.000 & 968.500 \\
\hline 5 & 267 & 200.250 & 350000 & 200000 & 200000 & 25000 & 975.250 \\
\hline \multirow[t]{2}{*}{6} & & & & & & & \\
\hline & 349 & 261.750 & 350.000 & 200.000 & 200.000 & 25.000 & 1.036 .750 \\
\hline 7 & 240 & 180.000 & 350.000 & 200.000 & 200.000 & 25.000 & 955.000 \\
\hline 8 & 268.1 & 201.075 & 350.000 & 200.000 & 200.000 & 25.000 & 976.075 \\
\hline \multirow[t]{2}{*}{9} & & 183.150 & & & & & 958.150 \\
\hline & 244.2 & 103.10 & 350.000 & 200.000 & 200.000 & 25.000 & טכנד. \\
\hline 10 & 273.3 & 204.975 & 350.000 & 200.000 & 200.000 & 25.000 & 979.975 \\
\hline \multicolumn{3}{|c|}{ Total Jarak : 2.639.1 } & & & \multicolumn{3}{|c|}{ Total Biaya : Rp. 9.729.330, } \\
\hline
\end{tabular}




\section{Hasil dan Diskusi}

Berdasarkan perhitungan yang telah dilakukan dengan Metode Nearest Neighbourdan Metode Nearest Insert, didapatkan beberapa alternative rute baru untuk pendistribusian sandal di Tasikmalaya. Rute-rute tersebut akan dibandingkan efektivitasnya berdasarkan keefektifan jarak yang ditempuh dan biaya transportasi yang dikeluarkan tanpa memperhatikan waktu. Solusi Vehicle Routing Problem pada kasus pendistribusian sandal di Tasikmalaya diselesaikan menggunakan metode Nearest Neighbour untuk pengurutan konsumen dengan mencari jarak yang terpendek dari konsumen yang ditempuh sebelumnya. Sehingga didapatkan rute yang terbaik adalah pada rute pertama dibentuk rute Tasikmalaya $\rightarrow$ Pamoyanan $\rightarrow$ Sukajadi $\rightarrow$ Dago $\rightarrow$ Sarijadi $\rightarrow$ Lembang $\rightarrow$ Tasikmalaya dengan jarak tempuh pada rute 1 sebesar $312.3 \mathrm{~km}$. Rute pendistribusian kedua adalah Tasikmalaya $\rightarrow$ Citarum $\rightarrow$ Sumur $\rightarrow$ Ciroyom $\rightarrow$ Andir $\rightarrow$ Cimahi $\rightarrow$ Tasikmalaya dengan jarak tempuh pada rute 2 sebesar $273.3 \mathrm{~km}$. Rute pendistribusian rute 3 adalah Tasikmalaya $\rightarrow$ Cikutra $\rightarrow$ Kiara Condong $\rightarrow$ Cibeunying $\rightarrow$ Caringin dengan jarak tempuh pada rute 3 sebesar $263 \mathrm{~km}$. Rute pendistribusian rute 4 adalah Tasikmalaya $\rightarrow$ Buah Batu $\rightarrow$ Ciwastra $\rightarrow$ Ciwidey $\rightarrow$ Tasikmalaya dengan jarak tempuh pada truk 4 sebesar $304.8 \mathrm{~km}$.Dan rute pendistribusian rute 5 adalah Tasikmalaya $\rightarrow$ Gede Bage $\rightarrow$ Ujung Berung $\rightarrow$ Cicaheum $\rightarrow$ Tasikmalaya dengan jarak tempuh pada rute 5 sebesar $226.5 \mathrm{~km}$.

Kemudian, solusi Vehicle Routing Problem pada kasus pendistribusian sandal di tasikmalaya diselesaikan menggunakan metode Nearest Insert. Pada penyelesaian metode ini yaitu dengan cara mencari konsumen atau kota yang jika ditambahkan ke subtour sebelumnya menghasilkan nilai jarak yang paling minimal. Cara tersebut dilakukan secara berulang sehingga seluruh konsumen masuk ke dalam subtour. Setiap penyisipan dihitung menggunakan persamaan yang terdapat pada metode ini.

Sehingga pada metodeNearest Insert didapatkan rute yang terbaik adalah pada rute pertama dibentuk Tasikmalaya $\rightarrow$ Pamoyanan $\rightarrow$ Sukajadi $\rightarrow$ Sarijadi $\rightarrow$ Dago $\rightarrow$ Lembang $\rightarrow$ Tasikmalaya dengan jarak tempuh pada rute 1 sebesar $309.6 \mathrm{~km}$. Rute pendistribusian kedua adalah Tasikmalaya $\rightarrow$ Citarum $\rightarrow$ Sumur $\rightarrow$ Ciroyom $\rightarrow$ Andir $\rightarrow$ Cimahi $\rightarrow$ Tasikmalaya dengan jarak tempuh pada rute 2 sebesar $273.3 \mathrm{~km}$. Rute pendistribusian rute 3 adalah Tasikmalaya $\rightarrow$ Cikutra $\rightarrow$ Cibeunying $\rightarrow$ Kiara Condong $\rightarrow$ Sarijadi $\rightarrow$ Tasikmalaya dengan jarak tempuh pada rute 3 sebesar $262.1 \mathrm{~km}$. Rute pendistribusian rute 4 adalah Tasikmalaya $\rightarrow$ Buah Batu $\rightarrow$ Ciwastra $\rightarrow$ Ciwidey $\rightarrow$ Tasikmalaya dengan jarak tempuh pada rute 4 sebesar $304.8 \mathrm{~km}$. Dan rute pendistribusian rute 5 adalah Tasikmalaya $\rightarrow$ Gede Bage $\rightarrow$ Ujung Berung $\rightarrow$ Cicaheum $\rightarrow$ Tasikmalaya dengan jarak tempuh pada rute 5 sebesar $226.5 \mathrm{~km}$. 


\section{Perbandingan Efektivitas Jarak}

Pada awalnya, perusahaan memiliki 10 rute dalam pendistribusian sandal.Jumlah rute tersebut dinilai sangat banyak mengingat jumlah kapasitas alat angkut yang dimiliki perusahaan sangat terbatas. Total jarak yang ditempuh pada perusahaan selama proses pengiriman produk pada 20 konsumennya adalah sebanyak $2.639 .1 \mathrm{~km}$. Setelah menggunakan metode Nearest Neighbour dan metode Nearest Insert perusahaan mengalami penurunan yang signifikan, rute distribusi produk tersebut dapat dipangkas menjadi 5 rute dari 10 rute.

Pada tabel diatas, secara keseluruhan rute dengan menggunakan Nearest Insertmenghasilkan total jarak tempuh yang paling minimal dibandingkan dengan menggunakan metode Nearest Neighbour. Rute Nearest Insert mampu melayani 20 konsumen yang terbagi dalam 5 rute dan menempuh perjalanan sebesar $1.376 .3 \mathrm{~km}$. Dengan total jarak tempuh tersebut, rute yang dihasilkan menggunakan metode Nearest Insert lebih efektif $3.6 \mathrm{~km}$ dari rute Nearest Neighbour dan lebih efektif $1.262 .8 \mathrm{~km}$ dari rute lama. Dengan demikian dapat dsimpulkan bahwa berdasarkan jarak yang ditempuh kendaraan, rute yang dibentuk menggunakan metode Nearest Insert menghasilkan rute yang paling efektif untuk menyelesaikan proses pendistribusian sandal.

\section{Perbandingan Efektivitas Biaya}

Pada awalnya, perusahaan memiliki 10 rute dalam pendistribusian sandal. Jumlah rute tersebut dinilai sangat banyak mengingat jumlah kapasitas alat angkut yang dimiliki perusahaan sangat terbatas. Total jarak yang ditempuh pada perusahaan selama proses pengiriman produk pada 20 konsumennya adalah sebanyak $2.639 .1 \mathrm{~km}$ hal tersebut membuat biaya transportasi pendistribusian sandal di perusahaan juga tidak sedikit yaitu sebesar Rp. 9.729.330. Setelah menggunakan metode Nearest Neighbour dan metode Nearest Insert perusahaan mengalami penurunan yang signifikan, rute distribusi produk tersebut dapat dipangkas menjadi 5 rute dari 10 rute. Secara keseluruhan biaya transportasi pendistribusian sandal dengan menggunakan NearestInsert menghasilkan biaya transportasi yang paling minimal dibandingkan dengan menggunakan metode Nearest Neighbour. Rute Nearest Insert mampu melayani 20 konsumen yang terbagi dalam 5 rute dan menempuh perjalanan sejauh $1376.3 \mathrm{~km}$ dan menghasilkan biaya transportasi sebesar Rp. 4.907.225. Dengan total biaya transportasi yang dikeluarkan tersebut, biaya yang dikeluarkan menggunakan metode Nearest Insert lebih efektif sebesar Rp. 2700,- dari biaya Nearest Neighbour dan lebih efektif sebesar Rp. 4.822.105 dari biaya transportasi awal perusahaan. Dengan demikian dapat disimpulkan bahwa berdasarkan biaya yang dikeluarkan pada saat pendistribusian, biaya yang dikeluarkan menggunakan metode Nearest Insert menghasilkan biaya yang paling efektif untuk proses pendistribusian sandal. 


\section{Analisis Perbandingan Metode Nearest Neighbour dan Metode Nearest Insert}

Berdasarkan penyeselasaian solusi Vehicle Routing Problem (VRP) dalam contoh kasus menggunakan metode Nearest Neighbour dan metode Nearest Insert dalam pengurutan konsumen pada rute dapat dilakukan analisis. Setelah menganalisis hasil setiap metode, untuk algoritma yang paling mudah dan sederhana yaitu metode Nearest Neighbour sedangkan untuk hasil yang memiliki nilai jarak terpendek dan biaya transportasi yang paling minimal adalah metode Nearest Insert.

Karena Metode yang optimal adalah metode yang menghasilkan nilai jarak dan biaya yang paling minimum.Sehingga dihasilkan bahwa metode yang optimal pada contoh kasus pendistribusian sandal adalah metode Nearest Insert.

\section{Kesimpulan}

Setelah melakukan analisis data pada contoh kasus yang diambil sebagai objerk penelitian, penulis dapat menarik objek sebagai berikut:

1. Dalam penentuan rute terbaik menggunakan metode Nearest Neighbour,terlebih dahulu mengelompokkan konsumen ke dalam rute dengan mengurutkan nilaisaving matrix dari yang terbesar hingga terkecil dengan memperhatikan batasan-batasan tertentu.

Setelah mendapatkanpengelompokkan konsumen dalm rute kemudian mengurutkan konsumen mana yang akan dilalui terlebih dahulu dengan cara mencari jarak yang terpendek dari konsumen yang telah dikunjungi sebelumnya.

Hasil penerapan pada metode Nearest Neighbour ini didapatkan rute pendistribusian terbaik yaitu pada rute pertama Tasikmalaya $\rightarrow$ Pamoyanan $\rightarrow$ Sukajadi $\rightarrow$ Dago $\rightarrow$ Sarijadi $\rightarrow$ Lembang $\rightarrow$ Tasikmalaya dengan jarak tempuh pada rute 1 sebesar 312.3 kmdan biaya transportasinya Rp. 1.009.225,- . Rute pendistribusian kedua adalah Tasikmalaya $\rightarrow$ Citarum $\rightarrow$

Sumur $\rightarrow$ Ciroyom $\rightarrow$ Andir $\rightarrow$ Cimahi $\rightarrow$ Tasikmalaya dengan jarak tempuh pada rute 2 sebesar 273.3 kmdan biaya transportasi sebesar Rp. 979.975. Rute pendistribusian rute 3 adalah Tasikmalaya $\rightarrow$ Cikutra $\rightarrow$ Kiara Condong $\rightarrow$ Cibeunying $\rightarrow$ Caringin $\rightarrow$ Tasikmalayadengan jarak tempuh pada rute 3 sebesar $263 \mathrm{~km}$ dan biaya transportasi sebesar Rp. 927.250. Rute pendistribusian rute 4 adalah Tasikmalaya $\rightarrow$ Buah Batu $\rightarrow$ Ciwastra $\rightarrow$ Ciwidey $\rightarrow$ Tasikmalaya dengan jarak tempuh pada truk 4 sebesar $304.8 \mathrm{~km}$ dan biaya transportasi sebesar Rp.1.003.600. Dan rute pendistribusian rute 5 adalah Tasikmalaya $\rightarrow$ Gede Bage $\rightarrow$ Ujung Berung $\rightarrow$ Cicaheum $\rightarrow$ Tasikmalaya dengan jarak tempuh pada rute 5 sebesar $226.5 \mathrm{kmdan}$ biaya transportasi sebesar Rp. $944.875,-$.

2. Dalam penentuan rute terbaik menggunakan metode Nearest Insert, terlebih dahulu mengelompokkan konsumen ke dalam rute dengan mengurutkan nilai saving matrix dari yang terbesar hingga terkecil dengan memperhatikan batasan-batasan tertentu. Setelah mendapatkan 
pengelompokkan konsumen dalm rute kemudian mengurutkan konsumen mana yang akan dilalui terlebih dahulu dengan cara menyisipkan konsumen pada rute yang sudah ada kemudian dicari konsumen mana yang menghasilkan jarak tempuh yang paling minimal .

Hasil penerapan pada metode Nearest Insert didapatkan rute pendistribusian terbaik yaitu pada rute pertama Tasikmalaya $\rightarrow$ Pamoyanan $\rightarrow$ Sukajadi $\rightarrow$ Sarijadi $\rightarrow$ Dago $\rightarrow$ Lembang $\rightarrow$ Tasikmalaya dengan jarak tempuh pada rute 1 sebesar $309.6 \mathrm{~km}$ dan biaya transportasi sebesar Rp. 1.007.200. Rute pendistribusian kedua adalah Tasikmalaya $\rightarrow$ Citarum $\rightarrow$ Sumur $\rightarrow$ Ciroyom $\rightarrow$ Andir $\rightarrow$ Cimahi $\rightarrow$ Tasikmalaya dengan jarak tempuh pada rute 2 sebesar $273.3 \mathrm{~km}$ dan biaya transportasi sebesar Rp. 979.975,-. Rute pendistribusian rute 3 adalah Tasikmalaya $\rightarrow$ Cikutra $\rightarrow$ Cibeunying $\rightarrow$ Kiara Condong $\rightarrow$ Sarijadi $\rightarrow$ Tasikmalaya dengan jarak tempuh pada rute 3 sebesar $262.1 \mathrm{~km}$ dan biaya transportasi sebesar Rp.971.575. Rute pendistribusian rute 4 adalah Tasikmalaya $\rightarrow$ Buah Batu $\rightarrow$ Ciwastra $\rightarrow$ Ciwidey $\rightarrow$ Tasikmalaya dengan jarak tempuh pada rute 4 sebesar $304.8 \mathrm{~km}$ dan biaya transportasi sebesar Rp. 1.003.600. Dan rute pendistribusian rute 5 adalah Tasikmalaya $\rightarrow$ Gede Bage $\rightarrow$ Ujung Berung $\rightarrow$ Cicaheum $\rightarrow$ Tasikmalaya dengan jarak tempuh pada rute 5 sebesar $226.5 \mathrm{~km}$ dan biaya transportasi sebesar Rp.944.875,-.

3. Berdasarkan penyelesaian solusi Vehicle Routing Problem (VRP) dalam kasus pendistribusian sandal di Tasikmalaya dalam pengurutan rute menggunakan metode Nearest Neighbour dan metode Nearst Insert, maka dihasilkan rute penditribusian terbaik.

Pada metode Nearest Neighbour didapatkan jarak tempuh sebesar $1.379 .9 \mathrm{~km}$ dengan biaya sebesar Rp.4.909.925,- sedangkan pada metode Nearest Insert didapatkan jarak tempuh sebesar 1.376.3km dengan biaya sebesar Rp.4.907.225 ,- Setelah menganalisa hasil dari setiap metode, didapatkan hasil yang memiliki nilai jarak terpendek dan biaya transportasi yang paling minimal adalah metode Nearest Insert. Sehingga dihasilkan bahwa metode yang optimal pada contoh kasus pendistribusian sandal adalah metode Nearest Insert.

\section{Referensi}

[1] Erlina, Mengoptimalkan Biaya Transportasi Untuk Penentuan Jalur Distribusi, Jurnal Penelitian IImu Teknik, 9(2), 143 - 150, 2009.

[2] S. Irnich, P. Toth, D. Vigo, The Vehicle Routing Problem, Philadelpia : Siam, 2002. 